\title{
Psychosocial factors during the first year after a coronary heart disease event in cases and referents. Secondary Prevention in Uppsala Primary Health Care Project (SUPRIM) Mats Gulliksson*1, Gunilla Burell ${ }^{1}$, Lennart Lundin ${ }^{2}$, Henrik Toss ${ }^{2}$ and Kurt Svärdsudd ${ }^{1}$
}

\author{
Address: ${ }^{1}$ Family Medicine and Clinical Epidemiology Section, Department of Public Health and Caring Sciences, Uppsala University, Uppsala \\ Sweden and 2 Internal Medicine Section, Department of Medical Sciences, Uppsala University Hospital, Uppsala, Sweden \\ Email: Mats Gulliksson* - mats.gulliksson@pubcare.uu.se; Gunilla Burell - gunilla.burell@pubcare.uu.se; \\ Lennart Lundin - lennart.lundin@akademiska.se; Henrik Toss - henrik.toss@akademiska.se; Kurt Svärdsudd - kurt.svardsudd@pubcare.uu.se \\ * Corresponding author
}

Published: 21 November 2007

BMC Cardiovascular Disorders 2007, 7:36 doi:10.1186/147I-2261-7-36

This article is available from: http://www.biomedcentral.com/|47|-226I/7/36

(c) 2007 Gulliksson et al; licensee BioMed Central Ltd.

This is an Open Access article distributed under the terms of the Creative Commons Attribution License (http://creativecommons.org/licenses/by/2.0), which permits unrestricted use, distribution, and reproduction in any medium, provided the original work is properly cited.

\begin{abstract}
Background: A large number of studies have reported on the psychosocial risk factor pattern prior to coronary heart disease events, but few have investigated the situation during the first year after an event, and none has been controlled. We therefore performed a case-referent study in which the prevalence of a number of psychosocial factors was evaluated.
\end{abstract}

Methods: Three hundred and forty-six coronary heart disease male and female cases no more than 75 years of age, discharged from hospital within the past 12 months, and 1038 referents from the general population, matched to the cases by age, sex and place of living, received a postal questionnaire in which information on lifestyle, psychosocial and quality of life measures were sought.

Results: The cases were, as expected, on sick leave to a larger extent than the referents, reported poorer fitness, poorer perceived health, fewer leisure time activities, but unexpectedly reported better social support, and more optimistic views of the future than the referents. There were no significant case-referent differences in everyday life stress, stressful life events, vital exhaustion, depressive mood, coping or life orientation test. However, women reported less favourable situations than men regarding stressful life events affecting others, vital exhaustion, depressive mood, coping, self-esteem, sleep, and symptom reporting, and female cases reported the most unfavourable situation of all groups.

Conclusion: In this first controlled study of the situation during the first year after a CHD event disease and gender status both appeared to be determinants of psychological well-being, with gender status apparently the strongest. This may have implications for cardiac rehabilitation programmes. 


\section{Background}

Cardiovascular disease (CVD) is the leading cause of death for men and women in the industrialized world, despite a decline in incidence [1] and mortality [2] in recent decades. CVD, and coronary heart disease (CHD) in particular, is influenced, positively or negatively, to a substantial degree, by lifestyle, and emotional and behavioural factors, in both first time event and recurrent events [3]. In recent decades psychosocial, emotional, and personality factors have come into focus [4-8].

In a number of studies psychosocial risk factors have been shown causally related to coronary heart disease incidents among men as well as among women, as summarized by Rosengren et al. [9] In these studies the psychosocial factors were measured prospectively before the incident. From a secondary prevention perspective it would be interesting to know what happens with these risk factor levels after a first event. A number of studies have addressed this question among men and women [10-16]. The findings from these studies generally show a tendency to improvement of the psychosocial situation during the first year after the event, even though the results are at variance, and most of the studies were small and uncontrolled.

The Secondary Prevention in Uppsala Primary Health Care (SUPRIM) project is an ongoing randomized controlled clinical trial in which two secondary cardiovascular prevention programmes are being evaluated in coronary artery disease patients. In this report we used baseline data from these patients within one year after the event and the corresponding data from matched referents from the general population, focussing on the psychosocial situation.

\section{Methods}

\section{Study population}

Patient inclusion criteria were age at most 75 years, discharged from Uppsala University Hospital after a myocardial infarction (MI) or percutaneous coronary intervention (PCI) or coronary artery bypass grafting (CABG), living in the hospital primary catchment area, referred back to the general practitioner (GP) within one year after the hospital admission, not having previously participated in similar programmes, being Swedish speaking, and being willing to participate in the study. All patients fulfilling the inclusion criteria were informed about the study during the first outpatient visit to the hospital two weeks after discharge. During a visit to the cardiology outpatient department three months after discharge the informed patients were formally invited to participate and verbal informed consent was obtained, standard requirement at the time. A written invitation letter to a baseline examination in the study was then mailed to the patients and those who accepted the invitation were eventually included. The recruitment period lasted from 1997 to 2002 and the follow-up data collection was completed in early 2007.

At the time of this report 778 consecutive patients had been considered for inclusion, of whom 287 did not fulfil the inclusion criteria, and 145 patients declined to participate, in most cases because of long distance from home to the hospital or lack of time. The remaining 346 patients (70.5\% of eligible cases) agreed to participate, of whom $176(50.9 \%)$ had been admitted for an MI, 119 (34.4\%) for a CABG, and $51(14.7 \%)$ for a PCI. Sixty-three MI patients had a PCI performed during the course of events and two had a CABG. There were no significant age, gender or diagnosis differences between participants and non-participants and no diagnosis differences between men and women. All included patients ("cases") answered a questionnaire at the baseline examination before randomisation and intervention.

All Swedish residents have a unique personal identification number, including information on date of birth and sex, stored in a population register that must be kept upto-date by law. For each case three referents, matched by age, sex and place of living, were sampled from the register in 2002. The 1038 referents received a postal questionnaire with relevant questions from the case questionnaire. Among the cases all 346 (100\%) responded and among the referents 610 (59\%), altogether 956 persons. For $92 \%$ of the cases at least one of the matched referents responded, yielding 318 case-referent constellations with one case and at least one referent.

\section{Social and demographic data}

At the time of the study more than 95\% of the Swedish population in these age groups were Caucasians and about $90 \%$ were native Swedes. Information on social background and lifestyle factors was obtained from the questionnaire. For this study marital status was classified as single (including divorced or widowed) or married/ cohabiting, educational level as university education or less, and smoking habits as currently smoker or not smoker. Snuff taking was classified accordingly. The participants were asked to indicate whether they had a job, had retired at normal old age retirement age (at the time of the data collection 65 years of age), or had received a disability pension. Non-retired subjects were asked whether they had been on sick leave during the past six months, and if so, for how many weeks.

\section{Psychosocial data}

The Everyday Life Stress Scale instrument [17] was used to assess the level of self-rated stress behaviour. It consists of two major themes, time urgency/impatience and easily 
aroused irritation/hostility. Responses to the 20 statements were given on four-point scales (0-3), higher scores indicating more stressful reactions. Internal consistency between the 20 items is high (Cronbach's alpha =0.90). A 5-point difference is of major clinical significance [18].

The Stressful Life Events instrument is derived from a more extensive life event scale [19]. The present version, whish comprises ten items, was previously used and validated in a Swedish study of women with cardiac disease [20]. Subjects are asked to indicate whether the stressful events asked about occurred during the past year (2), before the past year (1), or never $(0)$. For this report the events were subdivided into those affecting the respondent and others, high scores indicating more stressful life events.

Vital exhaustion was measured with the Maastricht Questionnaire [21], also used previously in a Swedish study of women with cardiac disease [20]. Responses to the 19 items were given on three-point scales (0-2), high scores indicating a high degree of vital exhaustion. In a validation of the instrument a difference of 5 points is considered to be of major inter- or intra-individual significance $[21,22]$.

The Depressive Mood Scale contains 20 items, selected from the Hamilton Depression Scale [23] and the Beck Depression Inventory (BDI) [24]. Both instruments are widely used, validated measures of depression severity during the past week $[23,24]$. The items were partially modified to achieve a standardised unidirectional response format. Possible responses were "not at all" (0), "not quite" (1), "quite well" (2), or "fully" (3), high scores indicating more depressive mood.

The Social Support Scale was originally developed by Henderson et al. [25], and later compiled into a short 30 item version by Undén and Orth-Gomer who also validated the short version [26]. In the present study, two of the four subscales were used, "availability of attachment" (AVAT), focusing on affectionately close relationships (social network quality), and "availability of social integration" (AVSI), estimating the size of the social network. AVAT has seven items, with response alternatives "yes" (1) or "no" (0), or "yes" (1), "not sufficient" (0) or "not at all" $(0)$, yielding total score ranges of $0-7$ points, high scores indicating more social integration and support. AVSI has six items, response alternatives ranging from "no one" to "more than 15 people" with a total score range of 0-30 points, high scores indicating a large social network.

The original Interpersonal Support Evaluation List (ISEL) was developed and validated by Cohen et al. [27]. It has four subscales with a total of 40 statements about the per- ceived availability of potential social resources. In this study a condensed 13-item version was used, with three subscales. "Appraisal" includes items on perceived availability of someone to talk with about problems. "Belonging" focuses on the availability of people to share activities with, and "Tangible" covers availability of material aid. Total score range (number of responses indicating support) was $0-13$ points, high scores indicating more interpersonal support.

The Mastery Subscale of Factor Items Measuring Coping Resources [28] was used to measure coping. Subjects are asked to indicate their agreement on a four-point scale ranging from "not at all" (0) to "completely" (3) for each of the seven items, high scores indicating more coping resources.

The Life Orientation Test (LOT) was initially developed and validated by Pearlin and Schooler to assess individual differences in generalized optimism versus pessimism [29]. It contains ten items with response alternatives ranging from "I disagree strongly" (0) to "I agree strongly" (3), high scores indicating optimism.

\section{Quality of life}

The Gothenburg Quality of Life Instrument, previously validated [30] and used in many studies, was used to measure quality-of-life aspects. For this report, the Complaint Score, the Perceived Health and the Activity Score subscales were used. The subscale Complaint Score is a list of 30 general symptoms, not intended to measure specific symptoms but rather the tendency to report symptoms. The subjects are asked to indicate what symptoms they had experienced during the past three months. In the Perceived Health subscale the subjects are asked to rate their work situation, home and family situation, fitness, mood, energy, patience, self-esteem, sleep, and well-being on seven-point interval scales ranging from "poor" $(=1)$ to "excellent, could not be better" (=7). The Activity Score subscale contains questions on 32 specified leisure time activities and two open alternatives covering six areas. The subjects are asked to indicate which of these activities they had performed during the last two months with response alternatives "never" (0), "occasionally" (1) or "often or regularly" (2). The scores were summed across the area and to an overall activity score, high scores indicating active lifestyle.

The Ladder of Life, developed by Cantril [31] and Andrews et al. [32], is often used as an indicator of wellbeing. The subjects are asked to rank their perceived present well-being, what it was one year ago, and what they think it will be one year from now, on ladder-like scales ranging from the worst $(=0)$ to the best possible situation $(=9)$, high scores indicating a better perceived or 
expected well-being. The instrument was used in the NIH Post-CABG Study $[33,34]$ and used in previous Swedish studies of subjects with CVD [35]. An validation shows that a 1-point difference is regarded as significant on the individual level [33-35]. The Research Ethics Committee at Uppsala University approved the study.

\section{Statistical analysis}

Data were analyzed using the SAS statistical programme package [36]. The frequency of missing data in returned questionnaires was less than $2 \%$. A power calculation was performed based on data on vital exhaustion from a controlled trial in female CHD patients and referents using the same instrument as we did [17]. Given a modest mean difference between cases and referents of 3.3 points with standard deviation 10.0, an $80 \%$ power would be obtained with a study population of 300 persons. The actual study population of 956 persons gave more than $95 \%$ power. Similar statistical power was obtained using the actual differences in activity score found in this study.

Crude differences in characteristics between the groups were tested with Student's t-test or analysis of variance for continuous data and the chi-square test for nominal or ordinal data. Differences in psychosocial and quality of life data between the groups were tested in conditional multiple linear regression or conditional ordinal logistic regression analyses adjusted for the influence of age, education, marital status and smoking habits, and adjusted means were generated using these procedures. All tests were two-tailed. To account for the many tests performed, $\mathrm{p}$-values $<0.005$ were considered to indicate statistical significance.

\section{Results}

\section{Characteristics of the study population}

Seventy-six per cent of the subjects were men and mean age was 66 years, Table 1. More than half were residents of urban areas, and one third were single. On average 23\% had a university education, $15 \%$ were daily smokers. Only men were snuff takers. On average 55\% were old age pensioners, and $12 \%$ had disability retirement benefits. Based on the 312 subjects who could be on sick leave $26 \%$ of the referents were on sick leave versus $68.8 \%$ of the female cases and $61.3 \%$ of the male cases.

\section{Psychosocial measures}

After adjustment for the influences of age, education, marital status and smoking habits, there were no differences between the groups regarding everyday life stress and stressful life events, Table 2. Events affecting others were more often reported by women than men, as were vital exhaustion $(\mathrm{p}<0.0001)$ and depressive mood scores $(\mathrm{p}<$ $0.001)$, while there were no significant differences between cases and referents for these variables. Cases reported higher social support scores than their referents. Men reported higher coping scores than women but with no significant differences between cases and referents. Women reported less optimism then men, and also the lowest optimism scores of all groups.

\section{Quality of life measures}

Quality of life data measured as well-being and activity score adjusted for the influence of age, education, marital status and smoking habits are shown in Table 3. Women reported a higher total well-being score then men. However, there were no significant differences between cases and referents or between men and women regarding work

Table I: Characteristics of the study population.

\begin{tabular}{|c|c|c|c|c|c|c|c|c|c|c|}
\hline & \multicolumn{4}{|c|}{ Women } & \multicolumn{4}{|c|}{ Men } & \multirow{3}{*}{$\begin{array}{c}\text { Sex } \\
\text { differences } \\
\text { P }\end{array}$} & \multirow{3}{*}{$\begin{array}{c}\text { Case-reference } \\
\text { differences } \\
\text { P }\end{array}$} \\
\hline & \multicolumn{2}{|c|}{ Cases } & \multicolumn{2}{|c|}{ Referents } & \multicolumn{2}{|r|}{ Cases } & \multicolumn{2}{|c|}{ Referents } & & \\
\hline & $\mathrm{n}$ & mean or $\%$ & $\mathrm{n}$ & mean or $\%$ & $\mathrm{n}$ & mean or $\%$ & $\mathrm{n}$ & mean or $\%$ & & \\
\hline Age, years & 82 & 67.5 & 149 & 66.9 & 264 & 64.9 & 461 & 65.1 & 0.0003 & 0.97 \\
\hline Urban dwellers, \% & 56 & 68.3 & 106 & 71.1 & 155 & 58.7 & 272 & 59.0 & 0.0022 & 0.77 \\
\hline Single, $\%$ & 29 & 35.4 & 64 & 43.2 & 33 & 12.6 & 94 & 20.7 & $<0.0001$ & 0.0041 \\
\hline University education, \% & 17 & 20.7 & 41 & 27.7 & 53 & 20.3 & 115 & 25.1 & 0.56 & 0.0634 \\
\hline Daily smokers, \% & 12 & 14.8 & 18 & 12.2 & 34 & 13.0 & 74 & 16.3 & $<0.0001$ & $<0.0001$ \\
\hline Snuff takers, \% & 0 & 0 & 1 & 0.7 & 26 & 10.0 & 57 & 12.5 & $<0.0001$ & 0.65 \\
\hline Old age pension, \% & 48 & 58.5 & 99 & 66.9 & 120 & 45.5 & 255 & 55.7 & 0.0016 & 0.0034 \\
\hline Disability pension, \% & 16 & 19.5 & 15 & 10.1 & 31 & 11.7 & 51 & II.I & 0.38 & 0.21 \\
\hline \multicolumn{11}{|l|}{ Sick-listed } \\
\hline Among all, \% & 15 & 19.2 & 15 & 10.1 & 80 & 31.5 & 47 & 10.3 & 0.12 & $<0.0001$ \\
\hline Among eligible, \% & 11 & 68.8 & 9 & 26.5 & 68 & 61.3 & 39 & 25.8 & 0.68 & $<0.0001$ \\
\hline
\end{tabular}

Characteristics of the study population. P-values refer to differences between men and women and between cases and referents in conditional analyses and $p<0.005$ were regarded as statistically significant. 
Table 2: Psychosocial measures.

\begin{tabular}{|c|c|c|c|c|c|c|c|}
\hline & \multirow[b]{2}{*}{ Score range } & \multicolumn{2}{|c|}{ Women } & \multicolumn{2}{|c|}{ Men } & \multirow{2}{*}{$\begin{array}{c}\begin{array}{c}\text { Sex } \\
\text { differences }\end{array} \\
P\end{array}$} & \multirow{2}{*}{$\begin{array}{c}\text { Case-referent } \\
\text { differences }\end{array}$} \\
\hline & & Cases & Referents & Cases & Referents & & \\
\hline$N$ & & 82 & 149 & 264 & $46 I$ & & \\
\hline Everyday Life Stress & $0-60$ & 17.5 & 18.3 & 18.9 & 18.6 & 0.75 & 0.92 \\
\hline Stressful Life Events & $0-20$ & 4.0 & 3.8 & 3.7 & 3.7 & 0.06 & 0.92 \\
\hline Affecting own person & $0-6$ & 1.0 & 0.8 & 1.4 & 1.1 & 0.15 & 0.057 \\
\hline Affecting others & $0-14$ & 3.0 & 3.0 & 2.3 & 2.6 & $<0.0001$ & 0.055 \\
\hline Vital exhaustion & $0-38$ & 16.8 & 15.6 & 12.2 & 12.7 & $<0.0001$ & 0.48 \\
\hline Depressive mood & $0-60$ & 21.4 & 20.0 & 16.8 & 17.9 & $<0.001$ & 0.31 \\
\hline Social support Scale & $0-39$ & 23.0 & 21.3 & 23.4 & 22.0 & 0.32 & 0.0001 \\
\hline Availability of attachment (AVAT) & $0-9$ & 8.3 & 7.8 & 7.9 & 7.6 & $<0.05$ & 0.0008 \\
\hline Availability of social integration (AVSI) & $0-30$ & 14.6 & 13.5 & 15.5 & 14.3 & 0.07 & 0.0007 \\
\hline Interpersonal support (ISEL) & $0-39$ & 29.1 & 27.7 & 28.7 & 28.0 & 0.81 & 0.0085 \\
\hline Appraisal & $0-15$ & 10.5 & 10.2 & 10.4 & 10.4 & 0.74 & 0.28 \\
\hline Belonging & $0-15$ & 11.6 & 10.9 & 11.3 & 10.8 & 0.45 & 0.0071 \\
\hline Tangible & $0-9$ & 7.0 & 6.7 & 7.0 & 6.8 & 0.92 & 0.09 \\
\hline Coping & $0-21$ & 14.5 & 14.2 & 15.7 & 15.3 & $<0.0001$ & 0.054 \\
\hline Optimism (LOT) & $0-30$ & 18.8 & 19.1 & 20.0 & 19.8 & 0.0046 & 0.44 \\
\hline
\end{tabular}

Psychosocial scale mean scores among female and male cases and referents, adjusted for the influence of age, education, marital status and smoking habits in conditional analyses. $\mathrm{p}<0.005$ were regarded as statistically significant.

situation, home and family situation, mood, energy and patience. Women reported significantly lower self-esteem, sleep, fitness and perceived health than men. Cases reported lower scores for fitness and perceived health than referents.
Women reported lower total activity, home outdoor activity, and physical activity scores than men. Cases reported lower total activity, home indoor activity, pleasure activity, and social activity scores than referents.

Women reported more complaint score symptoms $(10.2$ 95\%CI 9.2-11.2 for female referents and 10.4, 95\%CI

Table 3: Well-being and leisure time activity.

\begin{tabular}{|c|c|c|c|c|c|c|c|}
\hline & \multirow[b]{2}{*}{ Score range } & \multicolumn{2}{|c|}{ Women } & \multicolumn{2}{|c|}{ Men } & \multirow{2}{*}{$\begin{array}{c}\text { Sex differences } \\
\text { P }\end{array}$} & \multirow{2}{*}{$\begin{array}{c}\text { Case-referent differences } \\
\text { P }\end{array}$} \\
\hline & & Cases & Referents & Cases & Referents & & \\
\hline $\mathrm{N}$ & & 82 & 149 & 264 & 461 & & \\
\hline Well-being score & $9-63$ & 46.3 & 49.9 & 46.1 & 48.9 & 0.0001 & 0.11 \\
\hline Work situation & $\mathrm{I}-7$ & 4.7 & 4.8 & 4.7 & 5.0 & 0.28 & 0.0162 \\
\hline Home and family situation & $\mathrm{I}-7$ & 5.6 & 5.4 & 5.7 & 5.8 & 0.21 & 0.0091 \\
\hline Mood & $\mathrm{I}-7$ & 5.5 & 5.8 & 5.8 & 5.8 & 0.18 & 0.10 \\
\hline Energy & $1-7$ & 5.0 & 5.4 & 5.5 & 5.6 & 0.0264 & 0.09 \\
\hline Patience & $1-7$ & 5.6 & 5.8 & 5.6 & 5.8 & 0.41 & 0.0184 \\
\hline Self-esteem & $\mathrm{I}-7$ & 4.7 & 5.0 & 5.6 & 5.5 & $<0.0001$ & 0.70 \\
\hline Sleep & $1-7$ & 4.5 & 5.1 & 5.6 & 5.6 & $<0.0001$ & 0.19 \\
\hline Fitness & $1-7$ & 4.0 & 4.5 & 4.5 & 4.8 & 0.0049 & $<0.0008$ \\
\hline Perceived health & $\mathrm{I}-7$ & 4.5 & 5.1 & 5.0 & 5.3 & 0.0021 & 0.0001 \\
\hline Activity score & $0-64$ & 21.8 & 24.4 & 26.1 & 29.4 & $<0.0001$ & $<0.0001$ \\
\hline Home indoor activities & $0-10$ & 4.6 & 5.1 & 4.8 & 5.5 & 0.19 & 0.0002 \\
\hline Home outdoor activities & $0-8$ & 1.9 & 2.3 & 4.5 & 4.8 & $<0.0001$ & 0.0423 \\
\hline Physical activities & $0-14$ & 4.0 & 4.4 & 5.0 & 5.7 & $<0.0001$ & 0.0061 \\
\hline Pleasure & $0-16$ & 4.1 & 4.7 & 4.5 & 5.3 & 0.0106 & $<0.0001$ \\
\hline Social activities & $0-8$ & 4.7 & 5.2 & 4.8 & 5.3 & 0.82 & 0.0003 \\
\hline Clubs and associations & $0-8$ & 2.0 & 2.4 & 2.0 & 2.4 & 0.48 & 0.0125 \\
\hline
\end{tabular}

Well-being and Activity score among female and male cases and referents after adjustment for the influence of age, education, marital status and smoking habits in conditional analyses. $p<0.005$ were regarded as statistically significant. 
9.3-11.4 for female cases) than men $(8.2,95 \%$ CI $7.7-8.8$ for male referents and $8.1,95 \% \mathrm{CI} 7.4-8.8$ for male cases). The difference between men and women was significant $(p<0.0001)$ but not between cases and referents.

The rating of the general life situation a year ago, today, and what it is expected to be a year from now, is shown in Figure 1. Referents reported a small but non-significant change over the two years, whereas cases started on a low level and had a substantial increase of their life situation scores ending up with a higher score than referents. Especially female cases had a remarkable increase. The difference in slope between cases and referents was significant ( $p<0.005)$, but not the difference between women and men.

All results regarding psychosocial and quality of life measures were independent of diagnostic group and time from discharge from hospital to questionnaire response.

\section{Discussion}

Cases were old age pensioners or on sick leave to a larger extent than referents, had poorer fitness, poorer perceived health and lower activity scores, but better social support, and more optimistic views of the future. There were no significant case-referent differences in everyday life stress, stressful life events, vital exhaustion, depressive mood, coping or life orientation test. There were some interesting sex differences, such as stressful life events affecting oth- ers, vital exhaustion, depressive mood, coping, optimism (LOT), self-esteem, sleep, perceived health, total activity, home outdoor activity, physical activity, and symptom reporting where women generally had worse situations than men and female cases had the worst situation of all.

The response rate was moderate among the referents, approximately $60 \%$. However, within the matched quadruples more than $90 \%$ had at least one referent responder, and the result of the matching procedure was satisfactory. The potential bias caused by a differential number of responding referents in the matched quadruples was handled by conditional analyses, in which cases were compared only with their own referents. The number of referents per case is in this type of analysis of minor importance as long as there is at least one, since randomly sampled referents per case by definition are interchangeable. The frequency of missing data in returned questionnaires was low. Some of the questionnaires have been validated in their English version and some in their Swedish version. However, all questionnaires have been used extensively in previous studies. Moreover, in our study measurements among the cases were compared with those of matched referents. We have therefore no reason to believe that the data are affected by selection or other bias to such an extent that the conclusions have been affected. The limitations of the study include its cross-sectional nature, which limits the interpretations of cause and effect relationships.

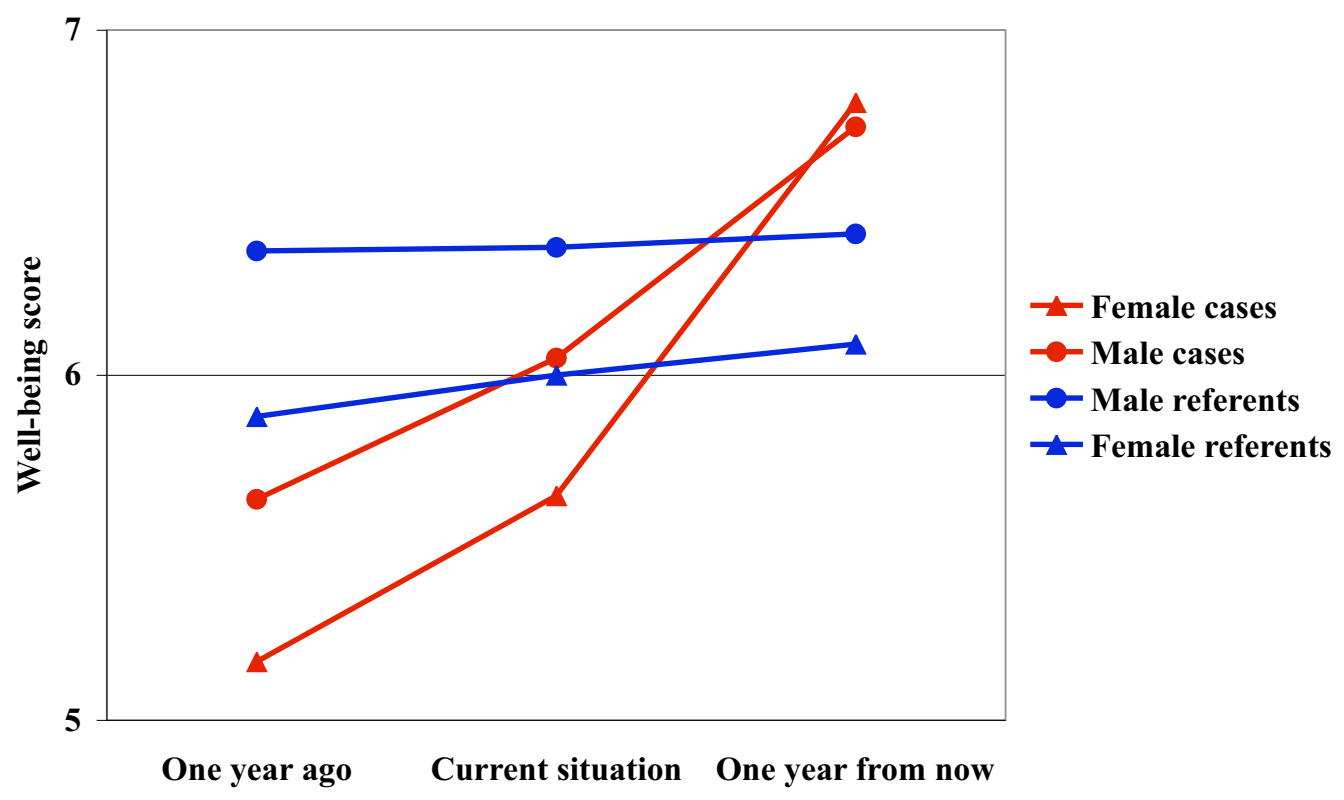

\section{Figure I}

Past, present time and future expectations. The Ladder of Life, expressing self-rated general life situation a year ago, presently and a year from now. The symbols refer to the time point given along the horizontal axis. 
The results regarding sick leave, perceived health, fitness, activity, and complaint score were all in accordance with expectations based on interpretations of findings in previous studies $[10,12,14]$, even though these studies were uncontrolled. The cases generally had less favourable situations than the referents with more objective and subjective illness, and more symptom reporting.

Unexpectedly, no significant differences between cases and referents were found with respect to everyday life stress (a measure of self-rated stress behaviour), stressful life events, vital exhaustion or depressive mood. The proportion of individuals with a clinically recognisable depression is somewhat difficult to assess. According to Beck's and Hamilton's criteria a score of 20 or more indicates depression. In this case that would mean half of the study population, cases as well as referents are depressed. This is unlikely and the cut-off level might be affected by cultural factors. Estimated from one of our databases about $2 \%$ of the Swedish population have a clinical depression, which in this case would mean that also cases are depressed in approximately $2 \%$. However, the proportion with a sub-clinical depression may by larger or much larger.

Previous research indicates that severe life events may be more common in CHD cases [6,9], although stressful life events as a CHD risk factor is controversial [8]. Even though the effects of stressful life events are supposed to be long-term, we found no significant differences between cases and referents the way we measured it within the first year after the incident. A possible explanation might be that the referent group included persons with a past history of CHD or other illnesses and therefore were more similar to the cases than a "healthy" group would have been. We have no data on the referents' medical history. However, the referents were sampled from the general population and the proportion of CHD cases in the group might be expected to be $5 \%$ or less. The probability that this proportion of $\mathrm{CHD}$ cases caused the non-significant case-referent difference in our study is small.

Another possibility might be that differences in marital status between men and women and cases and referents have affected the result. However, such differences were accounted for in the analyses. To our knowledge no other studies have addressed these issues. The large study population and the high statistical power of the present study indicate that it is unlikely that the differences were small due to chance. It is much more likely that they mirror a reality.

The evidence for stress as a CHD risk factor is more consistent $[8,9]$. The questionnaire on everyday life stress in our study had no specified time limit, but the wording is such that it can be interpreted as dealing with the present situation. The vital exhaustion questionnaire in this study covers the past three months and the depression questionnaire the past week. The cases may have reduced their stress related behaviour after the event, perhaps because they feel the need to be more relaxed, or they may withdraw from stress-provoking situations. It may be that the situation regarding stress, depression or vital exhaustion was quite different before the event, while during the first year after the event the cases' situation was more similar to the referents. This issue has not been addressed specifically in previous studies, but some support for an improvement of the physical and social function and mental health (depression) over time was reported by Kristofferzon et al. [14]. Again, the sample size and statistical power favour that our finding mirror a reality.

The cases reported a better social support situation than referents, significant for the Social Support Scale and the two subscales. This was un unexpected finding but may have the same explanation as stress related behaviour above, i.e., things may have calmed down during the first year after the event, the family and other social support providers may have increased their support as a result of the event. It may also reflect the short hospital based rehabilitation programme preceding the present programme and offered to the cases in the sample, in which family members were actively involved. This may to some extent have improved their psychological well-being, as well as involved the families in the rehabilitation. The possible change of social support over time after a CHD event has not been addressed explicitly previously, even though some evidence of perceived support have been presented [37]. We have no reason to believe that our findings are caused by chance.

The Ladder of Life instrument offers strong evidence that the cases' life situation changed dramatically from preevent to post-event. This change lends support to our speculation that several of the psychosocial measures we used may have improved considerably from before to after the event and reached or even surpassed the referent level.

There were major sex differences in the responses. Female referents and female cases scored significantly worse on complaints (physical and psychological symptoms), depressive mood, coping, stressful life events affecting others, optimism (LOT) and vital exhaustion than all men. This is in accordance with other studies showing that women tend to report (significantly) more health problems than do men after a CHD event [10-16]. Quality of life, assessed by the Ladder of Life, was significantly lower in both female cases and female referents as compared to men. Male referents rated the best quality of life, 
and female cases the worst. These results are supported by Agewall et al. who found that self-assessed quality of life after an MI was significantly lower in women than among men despite similar age, treatment and haemodynamic and laboratory data [16].

\section{Conclusion}

In conclusion, the results indicate that both sex and disease status are determinants of psychological well-being after a CHD event. However, sex seems to be the stronger determinant, since women generally do worse than men, and the high risk person in terms of low psychological well-being is the female cardiac case. Readily measured demographic and psychosocial risk factor data may assist in the identification of post-coronary event patients who are at increased risk of poor clinical outcomes. Prevention efforts and cardiac rehabilitation should be targeted to those with increased psychosocial burden, specifically women who experience greater disparities in recovery from cardiac events.

\section{Competing interests}

The author(s) declare that they have no competing interests.

\section{Authors' contributions}

All authors participated in designing the study. MG and KS obtained and edited additional register data. MG, GB and KS performed the analysis and drafted the manuscript. All authors participated in the discussions of the draft outline and contributed later with text revisions, table revisions and figure revisions. All authors have seen and approved the final version of the manuscript.

\section{Acknowledgements}

This study was supported by grants from Swedish Medical Research Council, Vårdal Foundation, the Swedish Council for Working Life and Social Research, the National Board of Health and Welfare, the National Heart and Lung Patient Association, Uppsala County Council, Uppsala Branch Office of the National Social Insurance Company, and Uppsala University.

\section{References}

I. Rosengren A, Spetz CL, Koster M, Hammar N, Rosen M: Sex differences in survival after myocardial infarction in Sweden: data from the Swedish National Acute Myocardial Infarction Register. Eur Heart | 200I, 22:3|4-322.

2. Tunstall-Pedoe H, Kuulasmaa K, Mahonen M, Tolonen H, Ruokokoski $\mathrm{E}$, Amouyel P: Contribution of trends in survival and coronaryevent rates to changes in coronary heart disease mortality: 10 -year results from 37 WHO MONICA project populations. Monitoring trends and determinants in cardiovascular disease. Lancet 1999, 353:1547-1557.

3. Wood D, De Backer G, Faergeman O, Graham I, Mancia G, Pyorala $\mathrm{K}$ : Prevention of coronary heart disease in clinical practice: recommendations of the Second Joint Task Force of European and other Societies on Coronary Prevention. Atherosclerosis 1998, 140:199-270.

4. Kuper H, Marmot M, Hemmingway H: Systematic review of prospective cohort studies of psychosocial factors in the etiology and prognosis of coronary heart disease. Semin Vasc Med 2002, 2:267-314.
5. Frasure-Smith N, Lesperance F, Gravel G, Masson A, Juneau M, Tilajic M, Bourassa MG: Social support, depression, and mortality during the first year after myocardial infarction. Circulation 2000, 101:1919-1924.

6. Rozanski A, Blumenthat JA, Kaplan J: Impact of psychological factors on the pathogenesis of cardiovascular disease and implications for therapy. Circulation 1999, 99:2192-2217.

7. Strike PC, Steptoe A: Psychosocial factors in the development of coronary artery disease. Prog Cardiovasc Dis 2004, 46:337-347.

8. Bunker SJ, Colquhoun DM, Esler MD, Hickie IB, Hunt D, Jelinek VM, Oldenburg BF, Peach HG, Ruth D, Tennant CC, Tonkin AM: "Stress" and coronary heart disease: psychosocial risk factors. Med J Aust 2003, 178:272-276.

9. Rosengren A, Hawken S, Ounpuu S, Sliwa K, Zubaid M, Almahameed WA, Blackett KN, Sitthi-amorn C, Sato H, Yusuf S: Association of psychosocial risk factors with risk of acute myocardial infarction in IIII9 cases and 13648 controls from 52 countries (the INTERHEART study): case-control study. Lancet 364(9438):953-62. 2004 Sep II-17

10. Kristofferzon ML, Lofmark R, Carlsson M: Perceived coping, social support, and quality of life I month after myocardial infarction: a comparison between Swedish women and men. Heart Lung 2005, 34(I):39-50.

II. McBurney CR, Eagle KA, Kline-Rogers EM, Cooper JV, Mani OCM, Smith DE, Erickson SR: Health-related quality of life in patients 7 months after a myocardial infarction: factors affecting the Short Form-1 2. Pharmacotherapy 2002, 22(I2):1616-22.

12. Brink E, Grankvist G, Karlson BW, Hallberg LRM: Health-related quality of life in women and men one year after acute myocardial infarction. Qual Life Res 2005, I4(3):749-57.

13. Norris CM, Ghali WA, Galbraith PD, Graham MM, Jensen LA, Knudtson ML: Women with coronary artery disease report worse health-related quality of life outcomes compared to men. Health Qual Life Outcomes 2:21. 2004 May 5

14. Kristofferzon ML, Lofmark R, Carlsson M: Coping, social support and quality of life over time after myocardial infarction. J Adv Nurs 2005, 52(2): I I3-24.

15. Kristofferzon ML, Lofmark R, Carlsson M: Myocardial infarction: gender differences in coping and social support. J Adv Nurs 2003, 44(4):360-74.

16. Agewall S, Berglund M, Henareh L: Reduced quality of life after myocardial infarction in women compared with men. Clin Cardiol 2004, 27(5):27I-4.

17. Claesson M, Burell G, Slunga Birgander L, Lindahl B, Asplund K: Psychosocial distress and impaired quality of life - targets neglected in the secondary prevention in women with ischemic heart disease. Eur J Cardiovasc Prev Rehab 2003, 10:258-266.

18. Burell G: Group psychotherapy in project New Life: Treatment of coronary prone behavior in coronary bypass graft surgery patients. In Heart \& Mind. The Practice of Cardiac Psychology Edited by: Allan R, Scheidt S. Washington DC: American Psychological Association; 1996

19. Dohrenwend BS, Dohrenwend BP, Dodson M, Shrout PE: Symptoms, hassels, social supports, and life events: problem of confounded measures. J Abnorm Psychol 1984, 93:222-230.

20. Orth-Gomér K, Horsten M, Wamala SP, Mittelman MA, Kirkeeide R, Svane B, Ryden L, Schenck-Gustafsson K: Social relations and extent and severity of coronary artery disease. The Stockholm Female Coronary Risk Study. Eur Heart J 1998, 19:1648-1656.

21. Appels A, Hoppener P, Mulder P: A questionnaire to assess premonitory symptoms of myocardial infarction. Int J Cardiol 1987, 17:15-24.

22. Appels A, Falger PR, Schouten EG: Vital exhaustion as risk indicator for myocardial infarction in women. J Psychosom Res 1993, 37:88I-90.

23. Hamilton M: Development of a rating scale for primary depressive illness. Br J Soc Clin Psychol 1967, 6:278-296.

24. Beck AT, Ward CH, Mendelson M, Mock J, Erbaug J: An inventory for measuring depression. Arch Gen Psychiatry 196I, 4:56I-57I.

25. Henderson S, Duncan-Jones P, Byrne DG, Scott R: Measuring social relationships. The Interview Schedule for Social Interaction. Psychol Med 1980, 10:723-734. 
26. Undén $\mathrm{AL}$, Orth-Gomér K: Development of a social support instrument for use in population surveys. Soc Sci Med 1989, 29: I387-1392.

27. Cohen S, Mermelstein R, Kamarck T, Hoberman HM: Measuring the functional components of social support. In Social support: Theory, research and applications Edited by: Sarason IG, Sarason BR. Dordrecht: Martinus Nijhoff Publishers; 1985:73-94.

28. Pearlin LI, Schooler C: The structure of coping. J Health Soc Behav 1978, I9:2-2|

29. Scheier MF, Carver CS: Effects of optimism on psychological and physical well-being: Theoretical overview and empirical update. Cognitive Therapy and Research 1992, 16:201-228.

30. Tibblin G, Tibblin B, Peciva S, Kullman S, Svärdsudd K: "The Göteborg Quality of Life Instrument"--an assessment of well-being and symptoms among men born 1913 and 1923. Methods and validity. Scand J Prim Health Care Suppl 1990, I ():33-38.

31. Cantril H: The pattern of human concerns New Brunswick, NJ: Rutgers University Press; 1965.

32. Andrews FM, Withey SB: Social indicators of well-being: American's perceptions of life quality New York: Plenum; 1976.

33. Czajkowski SM, Terrin M, Lindquist R, Hoogwerf B, Dupuis G, Shumaker SA, et al.: Comparison of preoperative characteristics of men and women undergoing coronary artery bypass grafting (the Post Coronary Artery Bypass Graft [CABG] Biobehavioral Study). Am J Cardiol 79:1017-24. 1997 Apr I5

34. Czajkowski SM: Health-related quality of life outcomes in clinical research: NHLBI policy and perspectives. Ann Thorac Surg 1998, 66(4): |486-7.

35. Olsson M, Janfjall H, Orth-Gomer K, Unden A, Rosenqvist M: Quality of life in octogenarians after valve replacement due to aortic stenosis. A prospective comparison with younger patients. Eur Heart J 1996, I 7:583-9.

36. SAS language and procedures Cary, NC: SAS Institute Inc; 2000.

37. Berkman LF, Blumenthal J, Burg M, Carney RM, Catellier D, Cowan MJ, Czajkowski SM, DeBusk R, Hosking J, Jaffe A, Kaufmann PG, Mithchell P, Norman J, Powell LH, Raczynski JM, Schneiderman N: Effects of treating depression and low perceived social support on clinical events after myocardial infarction: the Enhancing Recovery in Coronary Heart Disease Patients (ENRICHD) Randomized Trial. JAMA 2003, 289:3106-I6.

\section{Pre-publication history}

The pre-publication history for this paper can be accessed here:

http://www.biomedcentral.com/1471-2261/7/36/prepub

\section{Publish with Biomed Central and every scientist can read your work free of charge}

"BioMed Central will be the most significant development for disseminating the results of biomedical research in our lifetime. "

Sir Paul Nurse, Cancer Research UK

Your research papers will be:

- available free of charge to the entire biomedical community

- peer reviewed and published immediately upon acceptance

- cited in PubMed and archived on PubMed Central

- yours - you keep the copyright 